Eur J Clin Chem Clin Biochem

1995; 33:693-698

(C) 1995 Walter de Gruyter \& Co. Berlin · New York

\title{
Comparison of the Values of Basic Fibroblast Growth Factor Determined by an Immunoassay in the Sera of Patients with Traumatic Brain Injury and Enhanced Osteogenesis
} and the Effects of the Same Sera on the Fibroblast Growth In Vitro

\author{
By Renate Wildburger ${ }^{1}$, Neven Žarković ${ }^{2}$, Gerd Egger ${ }^{3}$, Walter Petek ${ }^{4}$, Andreas Meinitzer ${ }^{4}$, Suzana Borović ${ }^{2}$, \\ Kamelija Žarkovićs, Libin Li ${ }^{6}$, Igor Stipančić ${ }^{7}$, Milica Trbojević-Čepe ${ }^{8}$, Dubravka Čvoriščec ${ }^{8}$ \\ and Marko Doko 9 \\ 1 University Clinic of Traumatology, Graz, Austria \\ 2 "Rudjer Boskovic" Institute, Zagreb, Croatia \\ 3 Institute of General and Experimental Pathology, University of Graz, Graz, Austria \\ ${ }^{4}$ Laboratory of Clinical Chemistry, University Clinic of Surgery, Graz, Austria \\ s Clinical Hospital Center "Rebro", Institute of Neuropathology, Zagreb, Croatia \\ ${ }^{6}$ University of Traditional Chinese Medicine, Department of Experimental Neuroscience, Beijing, China, on leave \\ at Clinical Hospital Center "Rebro", Institute of Neuropathology, Zagreb, Croatia and "Rudjer Boskovic" Insti- \\ tute, Zagreb, Croatia \\ 7 General Hospital, Department of Surgery, Zagreb, Croatia \\ 8 Clinical Institute of Laboratory Diagnosis, University Clinic "Rebro", Zagreb, Croatia \\ 9 Clinical Hospital "Sisters of Mercy", Department of Surgery, Zagreb, Croatia
}

(Received January 23/May 2, 1995)

Summary: In patients with severe traumatic brain injury, the early healing of fractures is accompanied by hypertrophic callus formation or heterotopic ossifications, which might even result in ankylosis of the affected joints. Analysis of the sera of patients with traumatic brain injury revealed post-traumatic dynamic changes of basic fibroblast growth factor immunoreactivity, similar to those observed during fracture healing associated with enhanced osteogenesis. The aim of this study was to determine whether such changes in basic fibroblast growth factor concentrations could be related to the phenomenon of enhanced osteogenesis. Basic fibroblast growth factor immunoreactivity was determined (using an IEMA kit) in the sera of patients with traumatic brain injury and bone fractures $(n=8)$ and in the sera of patients with either traumatic brain injury alone $(n=10)$ or bone fractures alone $(n=7)$, and the effects of these sera on L929 fibroblast growth were analysed in vitro. The results did not prove a causative relationship between the changes of basic fibroblast growth factor immunoreactivity and in vitro growth promoting effects of the sera. However, it is apparent that, in addition to changes in the growth-promoting activity and basic fibroblast growth factor concentration of serum, other as yet unknown post-traumatic changes can cause enhanced osteogenesis.

\section{Introduction}

The phenomenon of excessive callus formation in patients with traumatic brain injury and fractures of long bones and large joints has often been described and is well documented $(1-4)$. Although the mechanisms un- derlying this phenomenon are still unknown, it seems that traumatic brain injury is accompanied by an increased amount of humoral growth stimulating factors in the serum, which may enhance osteogenesis (5). The 
growth factor that seems most likely to fulfil this role is basic fibroblast growth factor. Basic fibroblast growth factor was purified from bovine pituitary gland tissue by Gospodarowicz in 1975 (6). The activity of this growth factor in vivo is mainly described as induction of angiogenesis and stimulation of wound healing, while in vitro basic fibroblast growth factor influences the proliferation and differentiation of a wide variety of cells, such as fibroblasts, chondroblasts, osteoblasts, adrenocortical cells, etc. $(7-10)$. Altough the physiological role of basic fibroblast growth factor in bone metabolism still remains to be defined, its biological effects suggest that it may be an important regulator of bone growth and fracture healing. The most recent findings, using a novel human basic fibroblast growth factor immunoassay, show a change of basic fibroblast growth factor immunoreactivity in the sera of patients with traumatic brain injury alone or combined with the bone fractures, as well as in the sera of patients with bone fractures only (11). However, it is not certain whether the observed post-traumatic dynamic changes of basic fibroblast growth factor immunoreactivity have an influence on the cell growth promoting activity of the serum. The aim of this study was to test the possibility that basic fibroblast growth factor is one of the unidentified humoral factors that cause enhanced osteogenesis in patients with traumatic brain injury. Post-traumatic dynamic changes of basic fibroblast growth factor immunoreactivity in the sera of patients with traumatic brain injury alone or combined with the bone fractures, as well as in the sera of patients with bone fractures only, were therefore compared with the effects of these sera on the growth of L929 cells in vitro.

\section{Materials and Methods}

\section{Subjects}

Blood specimens were obtained from thirty-four subjects who were assigned to one of the following four groups.

Group I comprised 8 patients with traumatic brain injury and fractures of long bones or large joints. Six of the patients were male, and two female. The mean age (median value) was 18 years. Except for one patient the cause of injury was a traffic accident. All the patients were in coma from 3 to 20 days (average of 9 days). Five patients had intracerebral and/or intracranial haematomas, while three had diffuse oedema. Only one of the patients had to be craniotomised, while three patients required surgery for facial fractures. Six of the patients had cranial or facial fractures. All of them had fractures of the femur, one on both sides. Two patients also had fractures of the pelvis. The first callus formation occurred between the second and the fourth week after injury, and it was extended in every patient. One patient had heterotopic ossifications around the elbow and on the lateral femur condyl after Steinmann nail extension, and one patient had heterotopic ossifications in the small pelvis after a fracture of the iliac wing.

Group II included 10 patients with traumatic brain injury only, 8 male and two females. The median age value was 23.5 years. Nine of the patients were victims of traffic accidents, while one had fallen. All had either intracerebral or subdural haematoma or both. Four patients had to be craniotomised. The average coma lasted 11 days, while one patient died after 37 days of coma. Five of the patients had transitory neurological deficits, i. e. hemiparesis. All the surviving patients recovered.

Group III included 7 patients with fractures of long bones or large joints only. Five patients were male and two female. The age range was 18 to 64 years (median 26 years). They were mostly injured in traffic accidents. Six of the patients had fractures of the femur, one on both sides. One patient had a dislocation fracture of the elbow, while another one had fractures of both acetabula. The consolidation of the femur fractures and the fractures of the pelvis lasted about 12 weeks on average. No pathologically increased callus formation and no heterotopic ossifications were observed in these patients.

The patients of all three groups received sc. injections of heparin (2500-5000 I.U., depending on the body weight) daily during their stay in hospital (on the average for 4-6 weeks). Antibiotics were mostly given as prophylactics, analgesics were used occasionally, while steroids were not applied.

Group IV included 9 normal, healthy subjects, 5 male and 4 female. The age range was 20 to 45 years (median 24 years).

\section{Serum samples}

Sera were prepared from blood samples $(5-6 \mathrm{ml})$ taken from the patients, and the healthy subjects, between 8 and 10 a.m., at regular time intervals after the traumatic event. Blood was taken weekly after the injury, and after the release of patients from the hospital at intervals of two weeks for the following three months. The first samples were taken in the first two to four days after the accident. Blood samples were centrifuged within one hour at $+4^{\circ} \mathrm{C}$ for 10 $\mathrm{min}$ at $500 \mathrm{~g}$. Supernatants were collected, and their aliquots were immediately frozen and stored at $-30^{\circ} \mathrm{C}$.

\section{Determination of basic fibroblast growth factor immunoreactivity}

Basic fibroblast growth factor immunoreactivity was determined with a human basic fibroblast growth factor immunoassay (Quantikine $^{\mathrm{TM}}$ HS Assay, R \& D Systems, Inc., Minneapolis, USA). This assay employs the quantitative "sandwich" enzyme immunoassay technique (IEMA) using alkaline phosphatase as an amplification system. The assay is based on murine monoclonal antibodies against recombinant human basic fibroblast growth factor. Analysis of the serial dilution of recombinant human basic fibroblast growth factor standards and of the pooled normal human sera enriched with recombinant human basic fibroblast growth factor revealed an intra-assay precision $>86 \%$ (i.e., variation $<14 \%$ ) for three measurements of high $(>15 \mathrm{ng} / \mathrm{l})$ and low $(<2 \mathrm{ng} / \mathrm{l})$ basic fibroblast growth factor-containing samples: The sera samples were analysed using two batches of the IEMA kit which showed an interassay precision (for the standards and the chosen samples containing high or low basic fibroblast growth factor) greater than $73 \%$ (for high basic fibroblast growth factor-containing samples, i.e. $>15 \mathrm{ng} / \mathrm{l}$, variation was $<20 \%$ ). The serum samples used in the study were analysed in duplicate and the means of the results were calculated.

\section{In vitro bioassay}

The effects of sera from differently injured patients on cell growth were analysed using a standard $\left[{ }^{3} \mathrm{H}\right]$ thymidine assay and murine fibroblasts (L929 cell line). The cells were harvested from semiconfluent culture with $1 \mathrm{~g} / \mathrm{l}$ trypsin solution, then neutralized by addition of culture medium supplemented with $50 \mathrm{ml} / 1$ fetal calf serum (GIBCO, Germany). After washing the cells twice (10 min 
at $250 \mathrm{~g}$ ) with RPMI 1640 medium (without serum), the viability of the cells was tested by trypan blue exclusion, the number of live cells per litre of medium was adjusted to $4 \times 10^{8}$, and the cells were seeded in vitro. The seeding density of the cells cultured in 96-well microcytoplates (Greiner, Frickenhausen, Germany) was $2 \times 10^{4}$ cells per culture. The cells were incubated without serum for 24 hours at $37^{\circ} \mathrm{C}$ in a humidified air atmosphere with $5 \% \mathrm{CO}_{2}$. Afterwards, the sera obtained from the patients and the normal subjects were added to the quadruplicates of cultures at a final concentration of $10 \mathrm{~m} / 1$ (this particular concentration was chosen because preliminary testing showed higher serum concentrations to be too toxic) and the cells were further incubated for two days. The incorporation of $\left[{ }^{3} \mathrm{H}\right]$ thymidine (specific activity $962 \mathrm{GBq} / \mathrm{mmol}$, Amersham International, Plc., UK) added at $4 \mathrm{kBq}(0.1 \mu \mathrm{Ci})$ per culture was determined for the last 24 hours of cell growth, after harvesting the cells with the flow harvester (Skatron, Norway). Cell labelling was measured in a $\beta$-counter (Wallac 1209 Rackbeta liquid scintillation counter, Pharmacia, Sweden).

\section{Statistics}

The results were statistically evaluated by the Mann-Whitney $U$ test, and values of $P<0.05$ were considered significant.

\section{Results}

In figure 1, post-traumatic changes of serum basic fibroblast growth factor in patients with bone fractures are compared with the effects of the patient sera on L929 cell growth. Only a transient increase of basic fibroblast growth factor immunoreactivity (on average three-fold above the normal values) was observed in the second week after injury $(p<0.02)$. Afterwards, the values for the growth factor decreased to normal. Sera of these pa-

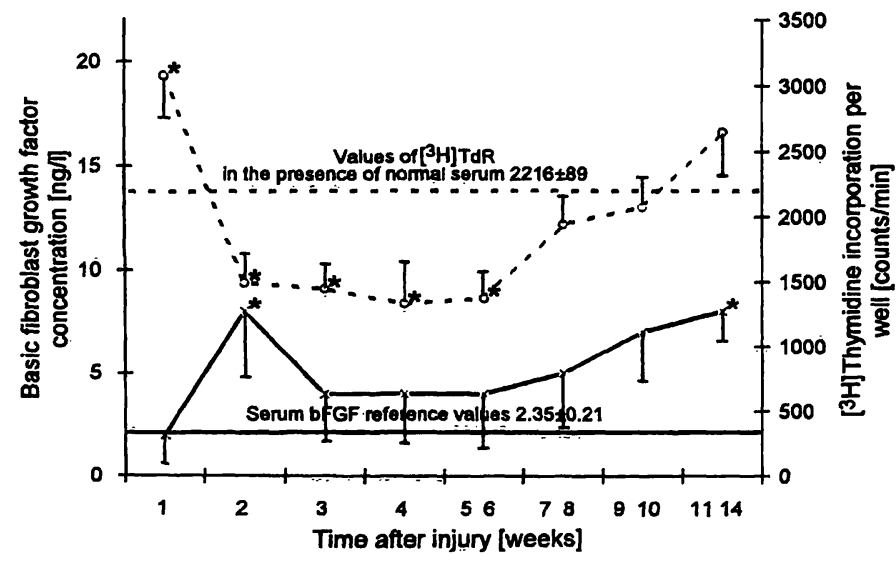

Fig. 1 Comparison of basic fibroblast growth factor (bFGF) immunoreactivity values in the sera of patients with bone fractures only $(N=7)$ and the effects of the same sera on the growth of L929 cells.

The results are presented as mean values \pm SEM of basic fibroblast growth factor $(-x-)$ and the mean values \pm SEM of $\left[{ }^{3} \mathrm{H}\right]$ thymidine incorporation (---o---) (counts per min and well) obtained for the same sera (each serum was added at $10 \mathrm{ml} / 1$ final concentration to the quadruplicates of cultures). Range of the reference values was $0.7-5.5 \mathrm{ng} / 1$ for basic fibroblast growth factor and 19152326 counts per min and well for the $\left[{ }^{3} \mathrm{H}\right]$ thymidine incorporation. * Significant difference $(P<0.05$ according to Mann-Whitney $U$ test) when compared with values obtained for healthy subjects $(\mathrm{N}=9)$. tients stimulated the cell growth more than the normal human sera only during the first week after injury, while the increase of basic fibroblast growth factor immunoreactivity during the second week was not accompanied by a further increase of growth promoting activity. On the contrary, from the second week onwards (until one and half months after injury) the sera of patients with bone fractures inhibited the cell growth $(P<0.05)$. After the end of the second month, the inhibitory effect of these sera was gradually lost. Although a slight but significant $(P<0.05)$ increase of the basic fibroblast growth factor concentration above normal was noticed in the period from the $11^{\text {th }}$ to the $14^{\text {th }}$ week after injury, the growth promoting activity of these sera was not higher than the stimulating effect of normal sera $(P>0.05)$. Sera obtained during the first week after injury from the patients suffering from traumatic brain injury only (without the bone fractures) also stimulated $(P<0.05)$ the cell growth (fig. 2). Sera from the same patients during the second post-traumatic week, however, inhibited the $\left[{ }^{3} \mathrm{H}\right]$ thymidine incorporation into L929 cells $(P<0.05)$. Sera obtained later from patients with traumatic brain injury did not affect L929 cell growth differently from the control sera (for the entire period, $P>0.05$ ). Sera from patients with brain injury also reached the maximal basic fibroblast growth factor values during the second week after injury. Afterwards the basic fibroblast growth factor concentration gradually decreased. However, the values determined in the sera of patients with traumatic brain injury were signifi-

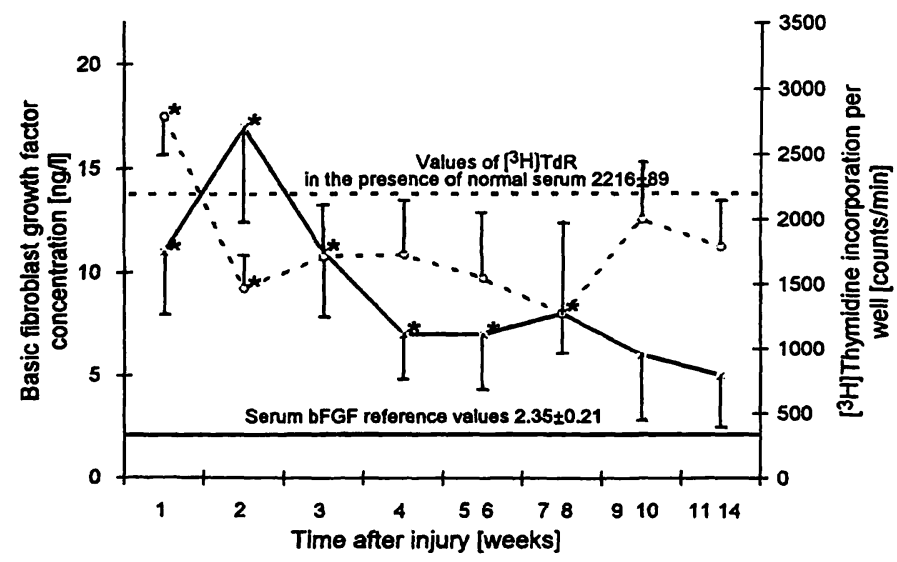

Fig. 2 Comparison of basic fibroblast (bFGF) growth factor immunoreactivity values in the sera of patients with traumatic brain injuries only $(\mathrm{N}=10)$ and the effects of the same sera on the growth of L929 cells.

The results are presented as mean values \pm SEM of basic fibroblast growth factor $(-x-)$ and the mean values \pm SEM of $\left[{ }^{3} \mathrm{H}\right]$ thymidine incorporation (---o---) (counts per min and well) obtained for the same sera (each serum was added at $10 \mathrm{ml} / \mathrm{l}$ final concentration to the quadruplicates of cultures). Range of the reference values was $0.7-5.5 \mathrm{ng} / \mathrm{l}$ for basic fibroblast growth factor and 19152326 counts per min and well for the $\left[{ }^{3} \mathrm{H}\right]$ thymidine incorporation. * Significant difference $(P<0.05$ according to Mann-Whitney $U$ test) when compared with values obtained for healthy subjects $(\mathrm{N}=9)$. 
cantly higher than normal values during the two months (from the $1^{\text {st }}$ until the $7-8^{\text {th }}$ week after injury, for the first three weeks $P<0.002$, afterwards $P<0.02$ or 0.05 ). The gradual decrease of the values for basic fibroblast growth factor immunoreactivity was not accompanied by any changes in the effects of these sera on the cell growth, i. e. from the second week onwards these sera did not show any significant effect on the $\left[{ }^{3} \mathrm{H}\right]$ thymidine incorporation into $\mathrm{L929}$ cells $(\mathrm{P}>0.05)$.

Furthermore, as can be seen from the figure 3, sera from patients with combined injury (traumatic brain injury and the fractures of the long bones) resembled that from patients in the previous two groups (figs 1,2 ) in that they stimulated L929 cell growth only during the first week after injury $(P<0.05)$. At the same time, a large increase of the serum basic fibroblast growth factor immunoreactivity was noticed $(\mathrm{P}<0.002)$; a further increase, however, was not associated with an increase of growth promoting activity of the sera. Inhibition of the $\left[{ }^{3} \mathrm{H}\right]$ thymidine incorporation into L929 cells was noticed $(\mathrm{P}<0.05)$ in the presence of the sera taken from the patients with brain injury and bone fractures during the second post-traumatic week (this was also noticed for the previous groups). Marked changes of the growth factor concentration in the sera of patients with traumatic brain injury and bone fractures were not associated with any particular changes in the effects of these sera on cultured L929 cells (for the entire subsequent

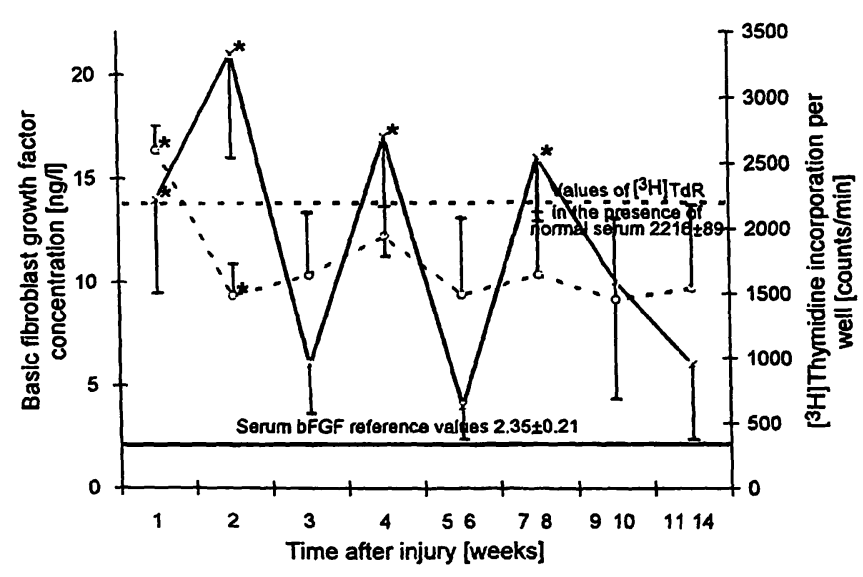

Fig. 3 Comparison of basic fibroblast growth factor (bFGF) immunoreactivity values in the sera of patients with traumatic brain injuries and bone fractures $(\mathrm{N}=8)$ and the effects of the same sera on the growth of $L 929$ cells.

The results are presented as mean values \pm SEM of basic fibroblast growth factor $(-\mathrm{x}-)$ and the mean values \pm SEM of $\left[{ }^{3} \mathrm{H}\right]$ thymidine incorporation (---0---) (counts per min and well) obtained for the same sera (each serum was added at $10 \mathrm{ml} / \mathrm{l}$ final concentration to the quadruplicates of cultures). Range of the reference values was $0.7-5.5 \mathrm{ng} / 1$ for basic fibroblast growth factor and 19152326 counts per min and well for the $\left[{ }^{3} \mathrm{H}\right]$ thymidine incorporation. * Significant difference $(P<0.05$ according to Mann-Whitney $U$ test) when compared with values obtained for healthy subjects $(\mathrm{N}=9)$. period, $P>0.05)$. Although significant differences in basic fibroblast growth factor immunoreactivity have been observed in the sera of differently injured patients (11), no differences were observed between the effects of these sera on the $\left[{ }^{3} \mathrm{H}\right]$ thymidine incorporation into L929 cells (for all the time intervals and all the groups, $P>0.1)$.

\section{Discussion}

The results do not indicate a causative relationship between the phenomenon of enhanced osteogenesis in patients with traumatic brain injury and the serum levels of basic fibroblast growth factor immunoreactivity. However, similar trends of post-traumatic changes of the growth factor concentration in the sera of the patients from all three groups and the effects of these sera on L929 cells growth in vitro were noticed. Hence, it could be assumed that basic fibroblast growth factor is one of the major factors in the serum showing biological effects on the $\mathrm{L} 929$ fibroblasts used for the $\left[{ }^{3} \mathrm{H}\right]$ thymidine incorporation bioassay. Such a conclusion seems to be credible, since basic fibroblast growth factor influences proliferation and differentiation in vitro of different types of cells, such as fibroblasts, chondroblasts, osteoblasts, adrenocortical cells, etc. (7-10). Moreover, its effects in vitro and in vivo indicate its involvement in normal and enhanced osteogenesis. It has been shown that basic fibroblast growth factor stimulates proliferation and differentiation of costal chondrocytes in vitro (12), as well as chondrocyte proliferation and cartilage healing in vivo (13). Furthermore, osteoblasts themselves synthesize basic fibroblast growth factor $(7,10$, 14), while transient treatment with basic fibroblast growth factor in vitro increases collagen synthesis in fetal rat osteoblasts (15). The hypothesis that basic fibroblast growth factor stored in the bone matrix has an influence on bone repair was proved (16), at least in a part, by the finding of dramatic hyperostosis in rat femurs after repeated intravenous administration of basic fibroblast growth factor (17). On the other hand, a significant transient increase of basic fibroblast growth factor immunoreactivity in the brain areas damaged by the traumatic brain injury or stroke was confirmed (1822). Hence, basic fibroblast growth factor is possibly also released from the damaged brain tissue, but it is not certain whether it could then modify the growth of cells at the distant "target" organ (bone). On the other hand, determination of the basic fibroblast growth factor values in serum (as well as its purification) is difficult, since the growth factor is present in very low concentrations and in different high $M_{\mathrm{r}}\left(M_{\mathrm{r}}>150000\right)$ forms which have the immunoreactivity of the free basic fibroblast growth factor $\left(M_{\mathrm{r}} 14000-16000\right)(8,23,24)$. The 
biochemical nature of high $M_{\mathrm{r}}$ forms of basic fibroblast growth factor is not entirely clarified, while it seems that at least some of them are conjugates of the growth factor with the serum proteins which act as cleavage enzymes (24). Furthermore, one of the characteristic features of basic fibroblast growth factor is its affinity to bind to heparin (7), while the binding of this growth factor to other serum components (proteins) also seems probable.

This was also indicated by the preliminary results (not presented) of the heparin affinity chromatography of the sera samples used in the study (pooled according to the groups). The high affinity of basic fibroblast growth factor immunoreactivity for heparin (more than $90 \%$ ) was not influenced by the type of traumatic event. Furthermore, membrane ultrafiltration of the pooled sera samples indicate that the $M_{\mathrm{r}}$ of the basic fibroblast growth factor immunoreactivity in the sera was above 30000 . Hence, it seems that the basic fibroblast growth factor immunoreactivity was represented by the higher $M_{\mathrm{r}}$ forms of the growth factor and not by the free basic fibroblast growth factor. However, further evaluation of the biochemical characteristics of the serum basic fibroblast growth factor immunoreactivity is necessary. On the other hand, since there was no major difference in the storage and preservation of sera (including heparin treatment during the initial post-traumatic phase) between the different groups of injured patients, it does not seem that the medicaments significantly influence the basic fibroblast growth factor immunoreactivity in the sera of the patients. On the other hand, in accordance with our results, the recent findings of Renfree et al. do not indicate that traumatic brain injury is associated with the phenomenon of heterotopic ossification by increased

\section{References}

1. Perkins R. Callus formation and the rate of healing of femoral fractures in patients with severe head injuries. J Bone Joint Surg 1987; 69-B(4):521-4.

2. Smith R. Head injury, fracture healing and callus. J Bone Joint Surg 1987; 69-B(4):518-20.

3. Spencer RF. The effect of head injury on fracture healing. $J$ Bone Joint Surg 1987; 69-B(4):525-8.

4. Wildburger R, Schweighofer F, Passler JM, Hofer HP. Heterotope Ossifikationen bei einem Patienten mit schwerem Schädelhirn Trauma. Zentrbl Chir 1992; 117:515-9.

5. Bidner SM, Rubins IM; Desjardins JV, Zukor DJ, Goltzman D. Evidence for a humoral mechanism for enhanced osteogenesis after head injury. J Bone Joint Surg 1990; 72$\mathrm{A}(8): 1144-9$.

6. Gospodarowicz D. Purification of a fibroblast growth factor from bovine pituitary. J Biol Chem 1975; 250:2515-20.

7. Gospodarowicz D, Ferrara N, Schweigerer L, Neufeld G. Structural characterization and biological functions of fibroblast growth factor. Endocrinol Rev 1987; 8:95-114.

8. Gospodarowicz D, Cheng J, Lui GM, Baird A, Böhlent P. Isolation of brain fibroblast growth factor by heparin-sepharose affinity chromatography: identity with pituitary growth promoting activity of the serum (25). Using an in vitro bioassay, these authors also observed a transient, non-specific, growth inhibiting effect of the injured patient's sera in vitro during the initial post-traumatic week (25). Thus, growth promoting as well as inhibiting activity of the serum of patients with traumatic brain injury seems to be mediated by numerous factors whose activity and/or concentration are changed after injury. However, since these sera showed similar post-traumatic dynamic changes of the basic fibroblast growth factor immunoreactivity and similar effects on the L929 cell growth, it was concluded that the phenomenon of enhanced osteogenesis in patients with traumatic brain injury is related to the post-traumatic dynamic changes of the serum basic fibroblast growth factor (11), but that the relationship between these two phenomena does not seem to be causative. More likely, the observed changes of the serum basic fibroblast growth factor immunoreactivity and enhanced osteogenesis are consequences of some systemic reaction to the intensive injury, manifested probably also by the increased toxicity of the serum during the second week after injury. Further evaluation of this hypothesis should not only aid the understanding the phenomenon of enhanced osteogenesis in patients with traumatic brain injury but also the understanding of the systemic reaction to the injury and the involvement of growth factors.

\section{Acknowledgements}

This study was supported by the Foundation of the Arbeitsgruppe für Osteosynthesefragen (AO/ASIF Foundation) and by the Croatian Ministry of Science and Technology.

fibroblast growth factor. Proc Natl Acad Sci USA 1984; 81:6963-7.

9. Rifkin DB, Moscatelli D. Recent developments in the cell biology of basic fibroblast growth factor. J Cell Biol 1989; 109:1-6.

10. Rodan SB, Rodan GA. Fibroblast growth factor and platelet derived growth factor. In: Gowen $\mathrm{M}$, editor. Cytokines and bone metabolism. Boca Raton, Florida: CRC Press, 1992:115-45.

11. Wildburger R, Zarkovic N, Egger G, Petek W, Zarkovic K, Hofer HP. Impaired bone fracture healing in patients with traumatic brain injury seems to be related to the changed concentration of the basic fibroblast growth factor (bFGF) immunoreactivity in the serum. Bone and Mineral 1994: 27:183-92.

12. Kato Y, Gospodarowicz D. Sulfated proteoglycan synthesis by rabbit costal chondrocytes growing in the presence and absence of fibroblast growth factor. J Cell Biol 1985; 100:477.

13. Cuevas $P$, Burgos J, Baird A. Basic fibroblast growth factor (bFGF) promotes cartilage repair in vivo. Biochem Biophys Res Commun 1988; 156:611-8.

14. Hauschka PV, Mavrakos AE, Lafrati MD, Doleman SE, Klagsbrun $\mathrm{M}$. Growth factors in bone matrix. Isolation of multiple 
types by affinity chromatography on heparin-sepharose. J Biol Chem 1986; 261:12665-74.

15. Canalis E, Centrella M, McCarthy Th. Effects of basic fibroblast growth factor on bone formation in vitro. J Clin Invest 1988; 81:1572-7.

16. Canalis E. Bone-related growth factors. Triangle 1988; 27:11-9.

17. Mazue G. Bertolero F, Garofano L, Brughera M, Carminati P. Experience with the preclinical assessment of basic fibroblast growth factor (bFGF). Toxicol-Lett 1992; 38:64-5.

18. Finklestein SP, Caday CG, Kano M, Berlove DJ, Hsu CY, Moskowitz $\mathrm{M}$, et al. Growth factor expression after stroke. Stroke 1990; 21 Suppl 11:122-4.

19. Frautschy SA, Walicke PA, Baird A. Localization of basic fibroblast growth factor and its mRNA after CNS injury. Brain Res 1991; 12:291-9.

20. Logan A, Frautschy SA, Gonzalez AM, Baird A. A time course for the focal elevation of synthesis of basic fibroblast growth factor and one of its high-affinity receptors (flg) following a localized cortical brain injury. J Neurosci 1992; 12:3828-37.

21. Riva MA, Gale K, Mocchetti I. Basic fibroblast growth factor mRNA increases in specific brain regions following convulsive seizures. Brain Res Mol Brain Res 1992; 15:311-8.
22. Takami K, Iwane $M$, Kiyota $Y$, Miyamoto $M$, Tsukuda $R$, Shiosaka S. Increase of basic fibroblast growth factor immunoreactivity and its mRNA level in rat brain following transient forebrain ischemia. Exp Brain Res 1992; 90:1-10.

23. Baird A, Esch F, Mormede P, Ueno N, Ling N, Bohlen P, et al. Molecular characterization of fibroblast growth factor: distribution and biological activities in yarious tissues. Recent Prog Horm Res 1986; 42:143-205.

24. Gauthier T, Maftouh M, Picard C. Rapid enzymatic degradation of [ $\left.{ }^{125} \mathrm{I}\right]$ Tyr $10-\mathrm{FGF}$ by serum in vitro and involvement in the determination of circulating FGF by RIA. Biochem Biophys Res Commun 1987: 145:775-81.

25. Renfree KJ, Banovac $\mathrm{K}$, Hornicek FJ, Lebwhol $\mathrm{NH}$, Villanueva PA, Nedd KJ. Evaluation of serum osteoblast mitogenic activity in spinal cord and head injury patients with acute heterotopic ossification. Spine 1994; 19:740-6.

Dr. Renate Wildburger

Universitätsklinik für Unfallchirurgie

Auenbruggerplatz 29

A-8010 Graz

Austria 